\title{
Association between sleep duration and blood pressure in adolescents
}

\author{
Inês Paciência ${ }^{1,2}$, Henrique Barros ${ }^{1,2,3}$, Joana Araújo ${ }^{1,2,3}$ and Elisabete Ramos ${ }^{1,2,3}$
}

In adults, sleep has an important role in the development of cardiovascular diseases. However, in young adolescents, the effect is unclear. The purpose of this cross-sectional study was to evaluate the association between sleep duration and blood pressure (BP) in subjects of 13 years of age. We evaluated 1771 adolescents as part of a population-based cohort (Epidemiological Health Investigation of Teenagers). Sleep duration was estimated based on the difference between self-reported usual bedtimes and wake-up times, and adolescents were classified into three categories: $\leqslant \mathbf{8 . 5} \mathrm{h}$ (reference class), $>\mathbf{8 . 5} \mathrm{h}$ and $<9.5 \mathrm{~h}$, and $\geqslant 9.5 \mathrm{~h}$. BP was measured using the auscultatory method and was classified as high if the systolic or diastolic BP was $\geqslant 90$ th percentile according to the American Academy of Pediatrics. To evaluate the association between BP and sleep duration, the odds ratios (ORs) and $95 \%$ confidence intervals ( $95 \% \mathrm{Cls}$ ) were computed by fitting binary logistic regression models with adjustments for caffeine intake and depressive symptoms in females and for caffeine intake and sports activities in males. The mean (s.d.) sleep duration was $9.0(0.80) \mathrm{h}$ per day. The prevalence of high BP was $32.5 \%$, higher in males (35.3\%) than in females (30.1\%, $P=0.019)$. After adjustment, in females, a positive association was found between sleep duration and high $\mathrm{BP}(>8.5$ and $<9.5 \mathrm{~h}: \mathrm{OR}=1.56,95 \% \mathrm{Cl} 1.07-2.27 ; \geqslant 9.5 \mathrm{~h}: \mathrm{OR}=1.83,95 \% \mathrm{Cl} 1.23-2.70$ ). Among males, no significant association was found between sleep duration and BP. Sleep duration was positively associated with BP in both sexes, although after adjustment for potential confounders, this association was significant only for female adolescents.

Hypertension Research (2013) 36, 747-752; doi:10.1038/hr.2013.36; published online 18 April 2013

Keywords: adolescent; blood pressure; cross-sectional; sleep duration

\section{INTRODUCTION}

Hypertension is an increasingly common health problem in adults $^{1}$ and is likely to become increasingly prevalent at younger ages. $^{2}$ Between 1988 and 1999, the prevalence of pre-hypertension and hypertension increased in United States children by $2.3 \%$ and $1 \%$, respectively. ${ }^{3}$

Several non-modifiable risk factors (such as age and sex) and modifiable risk factors (such as weight, lifestyle and salt intake) can have a role in the development of high blood pressure (BP) in adolescents. ${ }^{4}$ Modifiable risk factors are the most promising in terms of prevention because they could be targeted in health promotion interventions.

Thus, several studies have focused on the role of food intake ${ }^{1}$ and physical activity ${ }^{5}$ on BP. However, during the past few years, the roles of other modifiable factors, such as sleep duration, have gained attention. ${ }^{6-9}$

Different pathophysiological mechanisms may explain the association between sleep duration and BP. One important mechanism is related to the activity of the sympathetic nervous system. Sleep duration is associated with the sympathovagal balance, and most endocrine organs respond to changes in this balance, which might result in an increase or decrease in the release of hormones and in metabolism changes. ${ }^{10}$ Short sleep duration results in elevated cortisol levels, increased $\mathrm{BP},{ }^{11}$ overactivity of the renin-angiotensin-aldosterone system, endothelial dysfunction and renal impairment. ${ }^{7,12}$

The possible effects of sleep duration on BP are particularly relevant because during the last 30 years, there has been a decrease in the sleep duration of the general population, ${ }^{13,14}$ generally as a consequence of bedtime restriction. ${ }^{15}$ During adolescence, less parental control in defining the bedtime, increased school requirements and participation in extracurricular activities promote a reduction in sleep duration and increase the relevance of this factor as possible determinant of BP. ${ }^{16}$

Several studies have found that short sleep duration is a risk factor for hypertension during childhood. ${ }^{12,17}$ However, during adolescence, the association between sleep duration and BP is still unclear; some studies have found an inverse association, ${ }^{18}$ but others have reported no association. ${ }^{19,20}$ As the BP during adolescence is associated with the $\mathrm{BP}$ during adulthood, ${ }^{21,22}$ it is important to clarify the effect of this modifiable factor in young individuals to determine the potential to prevent hypertension and its consequences later in life.

\footnotetext{
${ }^{1}$ Institute of Public Health, University of Porto, Porto, Portugal; ${ }^{2}$ Department of Clinical Epidemiology, Predictive Medicine and Public Health, University of Porto Medical School, Porto, Portugal and ${ }^{3}$ Cardiovascular Research and Development Unit, University of Porto Medical School, Porto, Portugal

Correspondence: Professor E Ramos, Department of Clinical Epidemiology, Predictive Medicine and Public Health, University of Porto Medical School, Alameda Professor Hernâni Monteiro, Porto 4200-319, Portugal.

E-mail: eliramos@med.up.pt

Received 18 October 2012; revised 22 December 2012; accepted 15 January 2013; published online 18 April 2013
} 
The aim of this study was to evaluate the association between sleep duration and BP in 13-year-old subjects.

\section{METHODS}

A cross-sectional study was performed as part of the Epidemiological Health Investigation of Teenagers in Porto (EPITeen). Eligible participants were adolescents born in 1990 and enrolled at public and private schools in Porto during the 2003-2004 school year, as previously described. ${ }^{23}$ The ethics committee of Hospital S João approved the study, and informed consent was obtained from adolescents and their legal guardians.

The evaluation included self-administered questionnaires covering information on social, demographic and behavioral characteristics and on individual and family history of disease.

Sleep duration was estimated based on the difference between the usual bedtime ('What time do you usually go to bed?') and wake-up time ('What time do you usually wake up?') for weekdays when school is in session.

Sleep duration was categorized into three classes: $\leqslant 8.5 ;>8.5$ and $<9.5$; and $\geqslant 9.5 \mathrm{~h}$ per day. Categorization was performed approximately based on the tertiles of sleep duration.

Depressive symptomatology in adolescents was assessed by self-reported symptoms using the 'Beck Depression Inventory II' (BDI-II). ${ }^{24}$ The BDI-II is a 21 -item self-report scale intended to assess the existence and severity of current (past 2 weeks) depressive symptoms. The total score can range from 0 to 63, with higher scores reflecting more severe depression. The BDI-II was previously validated in Portuguese adolescents, and 13 was the cutoff indicated to define adolescents presenting depressive problems. ${ }^{25}$

As a measure of physical activity, we considered the practice of sports activities, defined as the participant being engaged in physical leisure time activity (not as a part of the school curriculum) on a repeated basis for at least 30 min per week.

The smoking habits and alcohol consumption of the adolescents were assessed by a self-administered questionnaire. Adolescents were classified regarding their use of alcohol and tobacco as never users if they had never consumed alcoholic drinks and if they had never smoked and as drinkers or smokers if they reported having used or experimented with those substances.

Parental education level was recorded as the number of successfully completed years of formal schooling, and we classified the adolescents according to the parent with the higher education level.

Information about a medical diagnosis of hypertension was obtained separately from the mother and the father. A family history of hypertension was considered present when at least one parent reported having been diagnosed with this condition.

A physical examination was also performed at school by a team of experienced nurses, nutritionists and physicians. Weight and height were obtained with the subject in light indoor clothes and no shoes. Weight was measured in kilograms $(\mathrm{kg})$, to the nearest tenth, using a digital scale, and height was measured in centimeters $(\mathrm{cm})$, to the nearest tenth, using a portable stadiometer. Two body mass index (BMI) categories were used in this study; these categories were based on the age- and sex-specific percentiles defined by the US Centers for Disease Control and Prevention (CDC): ${ }^{26}<85$ th percentile and $\geqslant 85$ th percentile.

BP was measured by trained doctors or nurses in the right arm using the auscultatory method with a standard mercury sphygmomanometer according to the recommendations of the National High Blood Pressure Education Program Working Group on High Blood Pressure in Children and Adolescents. ${ }^{27}$ Two measurements were performed after $10 \mathrm{~min}$ of rest, and the average was calculated. If the difference between the two measurements was $>5 \mathrm{~mm} \mathrm{Hg}$, a third measurement was performed, and the average of the two closest measurements was calculated. Hypertension was defined according to the quantitative criteria of the American Academy of Pediatrics: ${ }^{27}$ pre-hypertension was defined as an systolic BP (SBP) and/or diastolic BP (DBP) above the 90th percentile for sex, age and height when both were below the 95th percentile, and hypertension was defined as a SBP or DBP above the 95th percentile. To evaluate the association between sleep duration and $\mathrm{BP}$, the pre-hypertension and hypertension categories were grouped into one category-high BP (SBP and/or DBP was above the 90th percentile for sex, age and height).
Food intake was recorded using a food frequency questionnaire covering the previous 12 months. ${ }^{28}$ The food frequency questionnaire was validated for the Portuguese population and then adapted for adolescents, including foods more frequently eaten by this age group. To estimate nutrient intake, the Food Processor Plus program (version 7, ESHA Research, Salem, OR, USA), which is based on values from the US Department of Agriculture, was used. Caffeine intake was categorized according to the quartiles of intake into groups of $\leqslant 11.74$; $>11.74$ and $\leqslant 23.61 ;>23.61$ and $\leqslant 45.95$; and $>45.95 \mathrm{mg}$.

In total, 2787 adolescents born in 1990 were registered at the participating schools. It was not possible to contact 44 of these subjects, 583 did not return the signed informed consent form, and 2160 took part in at least some components of the study (77.5\% participation). Among the 2160 participating adolescents, 126 adolescents ( 66 females) for whom anthropometric measurements or the BP had not been taken and 263 (102 females) adolescents who did not report data on sleep were not included in this analysis. Thus, this study was based on data for 1771 adolescents (948 females).

Compared with the 1771 adolescents included in this analysis, the adolescents not included were more likely to be male than female and to have parents with a significant lower level of education. For the remaining variables (smoking, drinking, sports activities and BMI), no significant differences were found between those included and those not included.

\section{Statistical analysis}

The Shapiro-Wilk test was used to test for normality, and we used the Kruskal-Wallis test to compare continuous variables and the $\chi^{2}$ test to compare categorical variables. To evaluate the association between sleep duration and the categories of BP, odds ratios (ORs) and 95\% confidence intervals $(95 \% \mathrm{CI})$ were computed using unconditional binary logistic regression models. Crude models and models adjusted for BMI (model 1) and for caffeine intake and BDI in females and for caffeine intake and sports activities in males (model 2) were used.

All of the analyses were performed using the Statistical Package for the Social Sciences (SPSS Inc. Released 2009. PASW Statistics for Windows, Version 18.0. SPSS Inc., Chicago, IL, USA), and the level of statistical significance was set at 0.05 .

\section{RESULTS}

The mean (s.d.) of sleep duration was $9.0(0.80) \mathrm{h}$, being shorter for females $(9.0(0.82) \mathrm{h})$ than males $(9.1(0.78) \mathrm{h}, P=0.038)$. A total of 517 adolescents $(29.2 \%)$ reported sleeping $<8.5 \mathrm{~h}$ per day, whereas $556(31.4 \%)$ reported sleeping $>9.5 \mathrm{~h}$. Sleeping $<7 \mathrm{~h}$ was reported by $14(1.5 \%)$ females and $3(0.4 \%)$ males.

The prevalence of high BP (SBP or DBP above the 90th percentile for sex, age and height) was $32.5 \%$, and this prevalence was higher for males than females $(35.3 \%$ vs. $30.1 \%, P=0.019)$. The percentage of adolescents with high BP among those with a family history of hypertension was higher than among those with no family history of hypertension (34.4\% vs. $29.0 \%$, respectively, in females and $41.4 \%$ vs. $34.8 \%$, respectively, in males), although the results were not statistically significant for either sex. High BP was significantly associated with higher BMI and alcohol consumption.

Among female adolescents, the group of subjects who slept $\leqslant 8.5 \mathrm{~h}$ per day had a lower proportion of subjects with high BP, had parents with a higher level of education, were more frequently never drinkers and were more likely to be depressed. We did not find significant differences in sleep duration according to a family history of hypertension, smoking, participation in sports activities, caffeine intake, BMI category or age at menarche (Table 1).

Among males, we found differences in sleep duration with respect to parents' education level, sports activities and caffeine intake (Table 2).

Table 3 displays the ORs and 95\% CIs for high BP across categories of sleep duration by sex and adjusted for BMI (model 1) and for 
Table 1 Females' characteristics at 13 years of age, according to categories of sleep duration

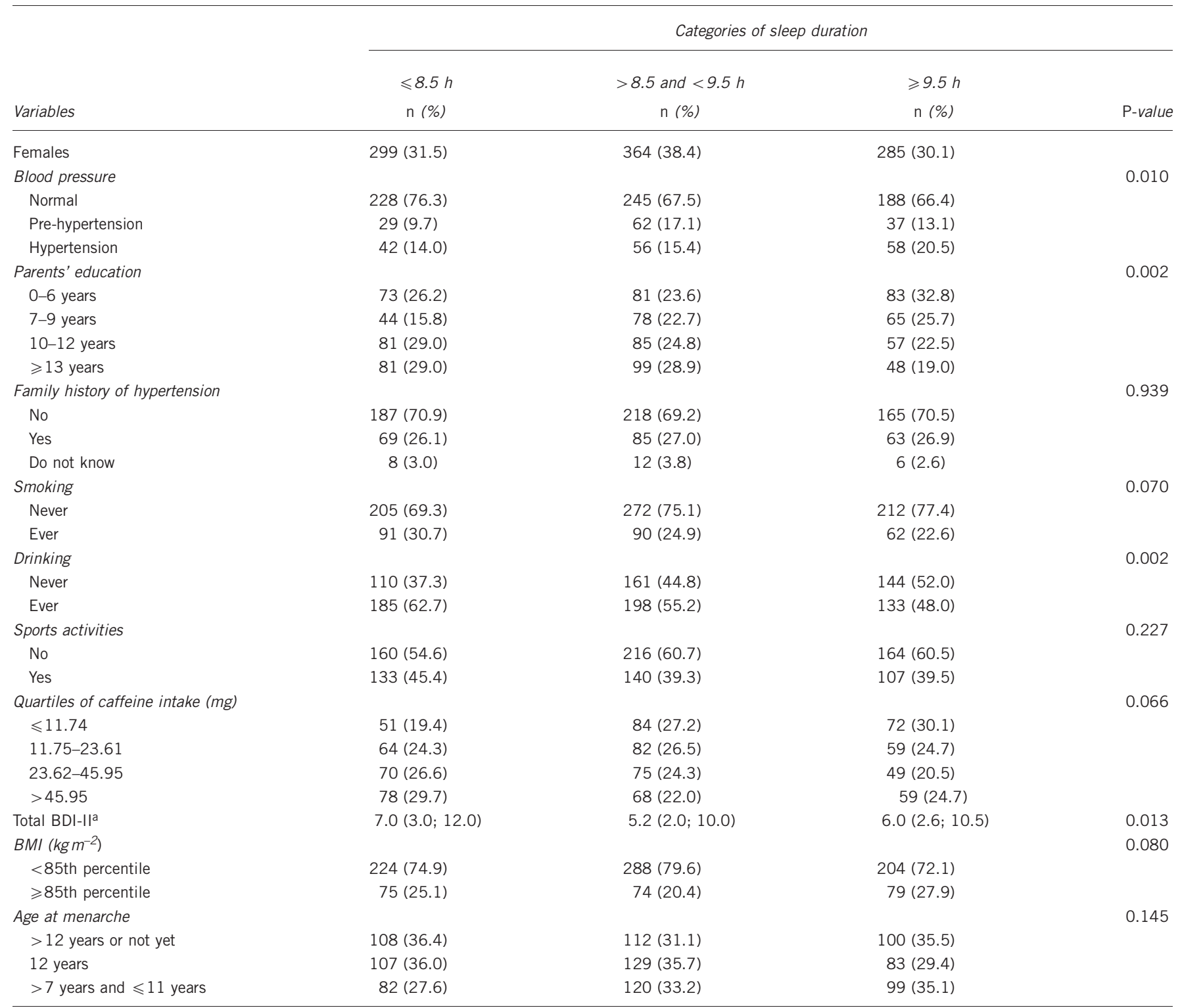

Abbreviations: BDI-II, Beck Depression Inventory II; BMI, body mass index.

a Results are presented as median (25-75th percentile).

caffeine intake and BDI in females and for caffeine intake and sports activities in males (model 2). Compared with those who slept $\leqslant 8.5 \mathrm{~h}$, females who slept more had a higher likelihood of having a high BP. After adjusting for BMI, caffeine intake and BDI, the magnitude of the association increased and a dose-response effect was found $(\mathrm{OR}=1.56$ (95\% CI 1.07-2.27) among those who slept between 8.5 and $9.5 \mathrm{~h}$ and $\mathrm{OR}=1.83$ (95\% CI 1.23-2.70) among those who slept $\geqslant 9.5 \mathrm{~h})$ ). Among males, there was a positive association between sleep duration and high BP, but this association did not reach significance.

\section{DISCUSSION}

In our study, we found that sleep duration was longer for males than for females, which is in accordance with other studies that reported a higher prevalence of insufficient sleep among female adolescents. ${ }^{16,29}$
Regarding the effect of sleep on BP, we found higher odds of being hypertensive among those who slept $\geqslant 9.5 \mathrm{~h}$ per day, and this association was statistically significant in females. This result is not in accordance with the results of several studies ${ }^{12,17}$ that found an increased SBP in short sleepers, but it is in accordance with the results of a study ${ }^{18}$ that found high BP values among those in the highest quartile for sleep duration (11.0-12.8 h).

Data from previous studies suggest that the association between sleep duration and BP may follow a J-shaped curve, with both short ${ }^{12,30}$ and long ${ }^{18}$ sleep duration being associated with an increased prevalence of hypertension. Our results, showing high BP among those with longer sleep durations, tend to support this hypothesis. Our reference class (those who sleep $\leqslant 8.5 \mathrm{~h}$ ) comprised primarily adolescents with sleep durations between 7.5 and $8.5 \mathrm{~h}$, and a very low proportion of short sleepers (sleep duration $<7.5 \mathrm{~h}$ ). The distribution 
Table 2 Males' characteristics at 13 years of age, according to categories of sleep duration

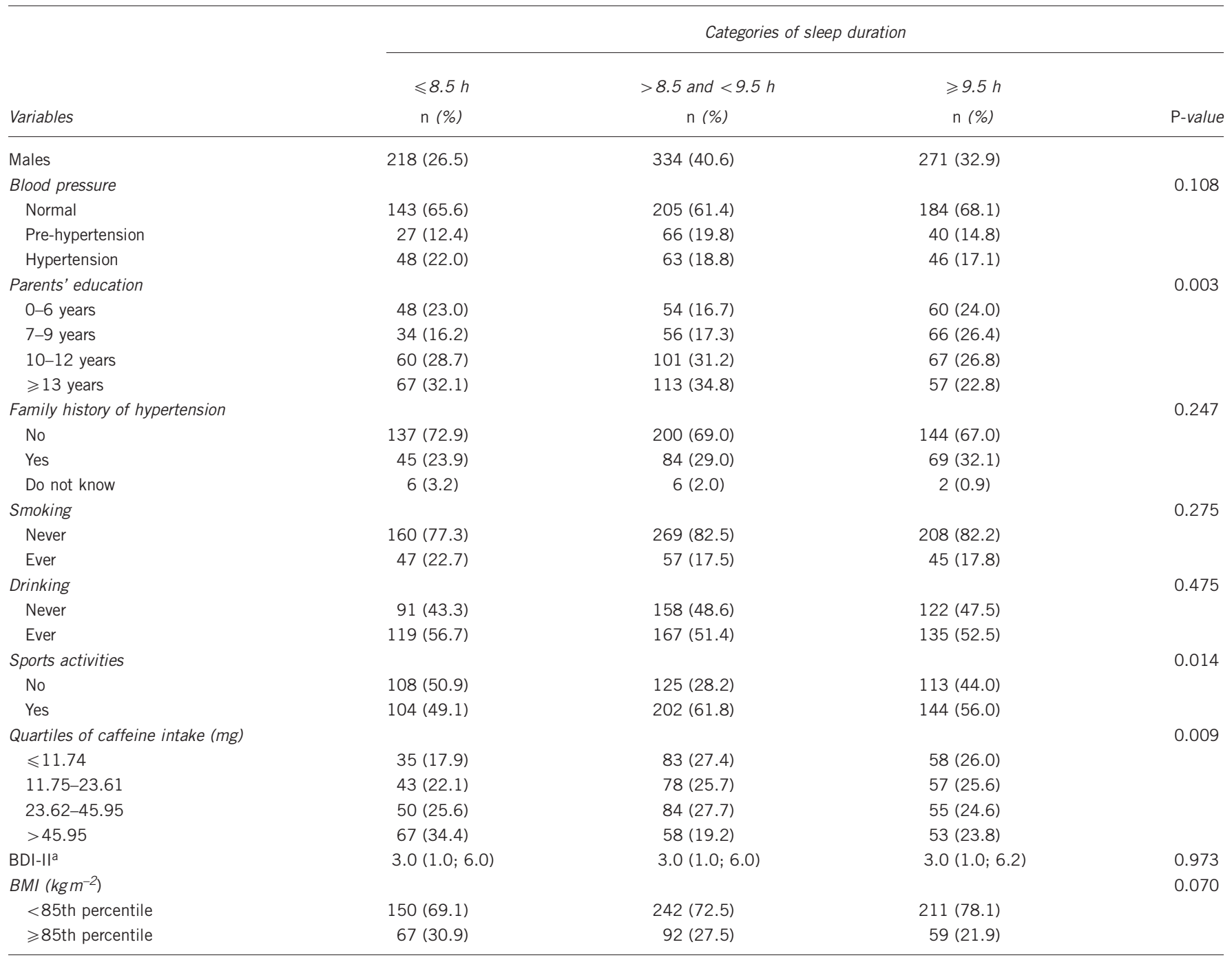

Abbreviations: BDI-II, Beck Depression Inventory II; BMI, body mass index. aResults are presented as median (25-75th percentile).

of sleep duration in our sample may have prevented us from identifying an association between short sleep duration and high BP.

The mechanism linking long sleep duration to hypertension has not been studied in depth and remains unclear. Some studies have shown that a long sleep duration is associated with less physical activity and consequently a higher $\mathrm{BP},{ }^{31}$ but this association was not found in our study. Another potential mechanism is related to the metabolism of cortisol; however, we could not evaluate the role of this mechanism because data on cortisol levels were not available.

We found a significant association between longer sleep duration and an increased risk of high BP only among females. In adults, the endocrine environment during menopause has been reported to be one possible explanation. ${ }^{6}$ A similar effect related to the effects of puberty may be expected during adolescence. The sex differences may be related to differences in the maturation stage: females are usually biologically more developed than males at the same chronological age. $^{32}$ Thus, it is acceptable to assume that females at this age need less sleep, making the effect of a long sleep duration more apparent. However, in our study, adjusting for age at menarche did not change the magnitude of the association.
Gottlieb et al. ${ }^{31}$ found that both short and long sleep durations were significantly associated with depressive symptoms. In our study, we also found higher values of depressive symptomatology (BDI) among females with lower and higher sleep durations. As depressive symptoms may be related with sleep disturbances ${ }^{33}$ and with $\mathrm{BP},{ }^{34}$ we decided to include this variable in the final model. Similar results were also found regarding caffeine intake..$^{35}$

One limitation of this study is the methodology used to estimate sleep duration. However, a study of high school adolescents found a moderate correlation between actigraphy results and self-reported total sleep time for weeknights $(r=0.53)$ but high correlations between actigraphy results and self-reported bedtimes $(r=0.70)$ and wake-up times $(r=0.77) .{ }^{36}$ Thus, even with the limitations regarding the accurate quantification of sleep time, we can accept that our measure is good enough to discriminate our participants according to their sleep duration.

Another limitation of our study is the BP measurement because BP may vary throughout the day and between days ${ }^{37}$ and the diagnosis of hypertension should be based on at least three separate measurements over a period of time. ${ }^{27}$ Our method of assessing BP may have 
Table 3 Association between sleep duration and high BP (SBP and/or DBP are above the 90th percentile for sex, age and height) in 13-yearold adolescents, by gender

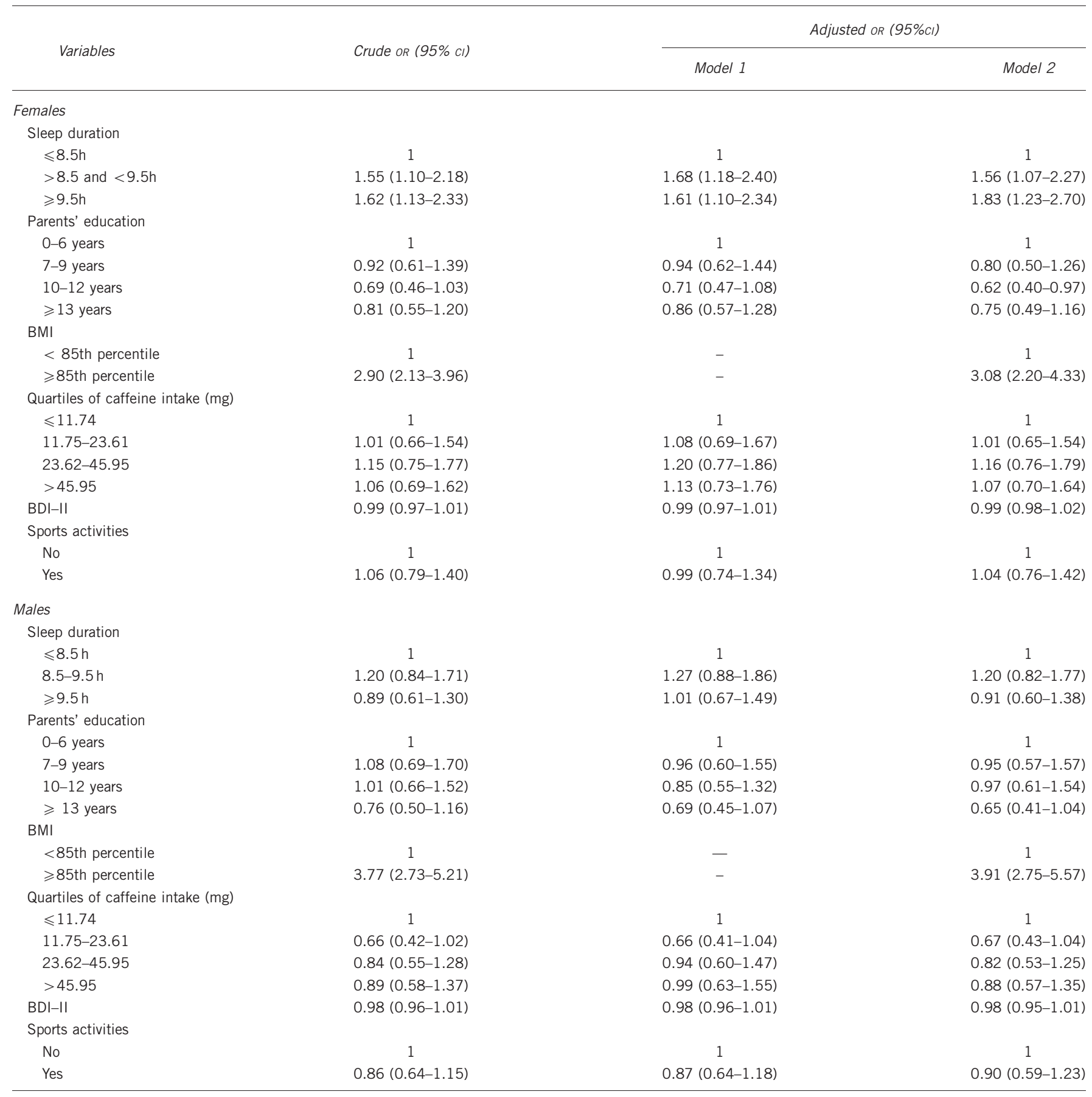

Abbreviations: BDI-II, Beck Depression Inventory II; BMI, body mass index; BP, blood pressure; Cl, confidence interval; DBP, diastolic BP; OR, odds ratio; SBP, systolic BP.

Model 1: OR adjusted for BMI in both genders.

Model 2: OR adjusted for caffeine intake (mg) and BDI in females and adjusted for caffeine intake (mg) and sports activities in males.

resulted in an overestimation of the prevalence of high BP because in repeated assessments, lower values would be expected. ${ }^{38,39}$ Nevertheless, the BP measurement was performed at school, in the adolescents' usual environment, which would have helped reduce any 'white-coat' effect. ${ }^{27}$

Our study was conducted using a representative sample of adolescents because school education is compulsory in Portugal until 15 years of age. We also had a high level of participation, and in general, the adolescents not included in the study were similar to those that were included with respect to all variables except sex and the parents' educational level. Differences related to sex were minimized by stratification; nevertheless, the included adolescents had parents with a higher education level. Several studies found that lower socioeconomic status can contribute to disparities in health, such as poor diet, lack of physical activity ${ }^{40}$ and changes in sleep duration. ${ }^{41,42}$ Wells et al. ${ }^{17}$ found that sleep patterns are associated 
with SES, with the wealthiest group having the shortest sleep duration. In addition, our results indicate that adolescents whose parents' education levels were higher were the subjects who reported shorter sleep durations. Thus, it is expected that our prevalence of short sleepers was overestimated. However, in our sample, the prevalence was so low that our associations are most likely not biased.

\section{CONCLUSION}

Our study provides evidence for an association between longer sleep duration and an increased likelihood of high BP in 13-year-old females, but no significant association was found for males. These results suggest that sleep duration might have a role in the etiology of hypertension, although a better understanding of the potential J-shaped effect is necessary.

\section{CONFLICT OF INTEREST}

The authors declare no conflict of interest.

\section{ACKNOWLEDGEMENTS}

This study was developed within the activities of the Cardiovascular Research and Development Unit (JNICT UI\&D 51/94) and was supported by the Portuguese Foundation for Science and Technology (grants FCOMP-01-0124FEDER-015750, and SFRH/BD/78153/2011 to JA). This study has not been published previously, and it is not under consideration for publication elsewhere.

1 Hajiar I, Kotchen TA. Trends in prevalence, awareness, treatment, and control of hypertension in the United States, 1988-2000. JAMA 2003; 290: 199-206.

2 McCrindle BW. Assessment and management of hypertension in children and adolescents. Nat Rev Cardiol 2010; 7: 155-163.

3 Din-Dzietham R, Liu Y, Bielo MV, Shamsa F. High blood pressure trends in children and adolescents in national surveys, 1963 to 2002. Circulation 2007; 116: 1488-1496.

4 Hajiar I, Kotchen JM, Kotchen TA. Hypertension: trends in prevalence, incidence, and control. Annu Rev Public Health 2006; 27: 465-490.

5 Forman JP, Stampfer MJ, Curhan GC. Diet and lifestyle risk factors associated with incident hypertension in women. JAMA 2009; 302: 401-411.

6 Cappuccio FP, Stranges S, Kandala NB, Miller MA, Taggart FM, Kumari M et al. Gender-specific associations of short sleep duration with prevalent and incident hypertension: the Whitehall II Study. Hypertension 2007; 50: 693-700.

7 Gangwisch JE, Heymsfield SB, Boden-Albala B, Buijs RM, Kreier F, Pickering TG Rundle AG, Zammit GK, Malaspina D. Short sleep duration as a risk factor for hypertension: analyses of the first National Health and Nutrition Examination Survey. Hypertension 2006; 47: 833-839.

8 Lofaso F, Coste A, Gilain L, Harf A, Guilleminault C, Goldenberg F. Sleep fragmentation as a risk factor for hypertension in middle-aged nonapneic snorers. Chest 1996; 109 896-900.

9 Fiorentini A, Valente R, Perciaccante A, Tubani L. Sleep's quality disorders in patients with hypertension and type 2 diabetes mellitus. Int J Cardiol 2007; 114: E50-E52.

10 Laila A, Ahmed SB. Metabolic, endocrine, and immune consequences of sleep deprivation. Open Respiratory Med J 2011; 5: 31-43.

11 Leproult R, Copinschi G, Buxton O, Van Cauter E. Sleep loss results in an elevation of cortisol levels the next evening. Sleep 1997; 20: 865-870.

12 Javaheri S, Storfer-Isser A, Rosen CL, Redline S. Sleep quality and elevated blood pressure in adolescents. Circulation 2008; 118: 1034-1040.

13 Spiegel K, Leproult R, Van Cauter E. Impact of sleep debt on metabolic and endocrine function. Lancet 1999; 354: 1435-1439.

14 Randler C. Sleep length in German children and adolescents: comparing 1907 with 2006-2008. Somnologie 2009; 13: 89-91.

15 Rajaratnam SM, Arendt J. Health in a 24-h society. Lancet 2001; 358: 999-1005.
16 Russo PM, Bruni O, Lucidi F, Ferri R, Violani C. Sleep habits and circadian preference in Italian children and adolescents. J Sleep Res 2007; 16: 163-169.

17 Wells JC, Hallal PC, Reichert FF, Menezes AM, Araujo CL, Victora CG. Sleep patterns and television viewing in relation to obesity and blood pressure: evidence from an adolescent Brazilian birth cohort. Int J Obes (Lond) 2008; 32: 1042-1049.

18 Sampei M, Dakeishi M, Wood DC, Murata K. Impact of total sleep duration on blood pressure in preschool children. Biomed Res 2006; 27: 111-115.

19 Shaikh WA, Patel M, Singh S. Association of sleep duration with arterial blood pressure profile of gujarati Indian adolescents. Indian J Community Med 2010; 35: 125-129.

20 Hitze B, Bosy-Westphal A, Bielfeldt F, Settler U, Plachta-Danielzik S, Pfeuffer M, Schrezenmeir J, Mönig H, Müller MJ. Determinants and impact of sleep duration in children and adolescents: data of the Kiel Obesity Prevention Study. Eur J Clin Nutr 2009; 63: 739-746.

21 Lurbe E. Childhood blood pressure: a window to adult hypertension. J Hypertension 2003; 21: 2001-2003.

22 Sun SS, Grave GD, Siervogel RM, Pickoff AA, Arslanian SS, Daniels SR. Systolic blood pressure in childhood predicts hypertension and metabolic syndrome later in life. Pediatrics 2007; 119: 237-246.

23 Ramos E, Barros H. Family and school determinants of overweight in 13-year-old Portuguese adolescents. Acta Pædiatrica 2007; 96: 281-286.

24 Beck A, Steer R, Brown G. Manual for the Beck Depression Inventory-II. Psychological, San Antonio, TX, USA, 1996.

25 Coelho R, Martins A, Barros H. Clinical profiles relating gender and depressive symptoms among adolescents ascertained by the Beck Depression Inventory II. Eur Psychiatry 2002; 17: 222-226

26 Kuczmarski RJ, Ogden CL, Grummer-Strawn LM, Flegal KM, Guo SS, Wei R, Mei Z, Curtin LR, Roche AF, Johnson CL. CDC growth charts: United States. Adv Data 2000; 314: 1-27.

27 National High Blood Pressure Education Program Working Group on High Blood Pressure in Children and Adolescents. The fourth report on the diagnosis, evaluation, and treatment of high blood pressure in children and adolescents. Pediatrics 2004; 114: 555-576.

28 Araujo J, Severo M, Lopes C, Ramos E. Food sources of nutrients among 13-year-old Portuguese adolescents. Public Health Nutr 2011: 1-9.

29 Eaton DK, McKnight-Eily LR, Lowry R, Perry GS, Presley-Cantrell L, Croft JB. Prevalence of insufficient, borderline, and optimal hours of sleep among high school students - United States, 2007. J Adolesc Health 2010; 46: 399-401.

30 Lemola S, Raikkonen K, Scheier MF, Matthews KA, Pesonen AK, Heinonen K, Lahti J, Komsi N, Paavonen JE, Kajantie E. Sleep quantity, quality and optimism in children. J Sleep Res 2010; 20 (1 Pt 1), 12-20.

31 Gottlieb DJ, Redline S, Nieto FJ, Baldwin CM, Newman AB, Resnick HE, Punjabi NM Association of usual sleep duration with hypertension: the Sleep Heart Health Study. Sleep 2006; 29: 1009-1014.

32 Tanner JM, Whitehouse RH. Clinical longitudinal standards for height, weight, height velocity, weight velocity, and stages of puberty. Arch Dis Child 1976; 51: 170-179.

33 Pasch KE, Laska MN, Lytle LA, Moe SG. Adolescent sleep, risk behaviors, and depressive symptoms: are they linked? Am J Health Behav 2010; 34: 237-248.

34 Davidson K, Jonas BS, Dixon KE, Markovitz JH. Do depression symptoms predict early hypertension incidence in young adults in the CARDIA study? Coronary Artery Risk Development in Young Adults. Arch Intern Med 2000; 160: 1495-1500.

35 Temple JL. Caffeine use in children: what we know, what we have left to learn, and why we should worry. Neurosci Biobehav Rev 2009; 33: 793-806.

36 Wolfson AR, Carskadon MA, Acebo C, Seifer R, Fallone G, Labyak SE, Martin JL. Evidence for the validity of a sleep habits survey for adolescents. Sleep 2003; 26 213-216.

37 Bovet P, Gervasoni JP, Ross AG, Mkamba M, Mtasiwa DM, Lengeler C, Burnier M, Paccaud $F$. Assessing the prevalence of hypertension in populations: are we doing it right? J Hypertension 2003; 21: 509-517.

38 Sorof JM, Lai D, Turner J, Poffenbarger T, Portman RJ. Overweight, ethnicity, and the prevalence of hypertension in school-aged children. Pediatrics 2004; 113 (3 Pt 1), 475-482.

39 Barnett AG, van der Pols JC, Dobson AJ. Regression to the mean: what it is and how to deal with it. Int J Epidemiol 2005; 34: 215-220.

40 Pamuk E, Makuc D, Heck K, Reuben C, Lochner K. Health, United States, 1998 Socioeconomic Status and Health Chartbook. National Center for Health Statistics, MD 1998.

41 Bixler E. Sleep and society: an epidemiological perspective. Sleep Med 2009; 10 (Suppl 1), S3-S6.

42 McLaughlin Crabtree V, Beal Korhonen J, Montgomery-Downs HE, Faye Jones V, O'Brien LM, Gozal D. Cultural influences on the bedtime behaviors of young children. Sleep Med 2005; 6: 319-324. 